\title{
A 'what-if' scenario: Nipah virus attacks pig trade chains in Thailand
}

\author{
Phrutsamon Wongnak ${ }^{1,2}$, Weerapong Thanapongtharm ${ }^{3}$, Worapan Kusakunniran ${ }^{4}$, Sarattha Karnjanapreechakorn ${ }^{4}$, \\ Krittanat Sutassananon ${ }^{4}$, Wantanee Kalpravidh ${ }^{5}$, Kachen Wongsathapornchai ${ }^{6}$ and Anuwat Wiratsudakul ${ }^{*}$ (i)
}

\begin{abstract}
Background: Nipah virus (NiV) is a fatal zoonotic agent that was first identified amongst pig farmers in Malaysia in 1998, in an outbreak that resulted in 105 fatal human cases. That epidemic arose from a chain of infection, initiating from bats to pigs, and which then spilled over from pigs to humans. In Thailand, bat-pig-human communities can be observed across the country, particularly in the central plain. The present study therefore aimed to identify highrisk areas for potential NiV outbreaks and to model how the virus is likely to spread. Multi-criteria decision analysis (MCDA) and weighted linear combination (WLC) were employed to produce the NiV risk map. The map was then overlaid with the nationwide pig movement network to identify the index subdistricts in which NiV may emerge. Subsequently, susceptible-exposed-infectious-removed (SEIR) modeling was used to simulate NiV spread within each subdistrict, and network modeling was used to illustrate how the virus disperses across subdistricts.

Results: Based on the MCDA and pig movement data, 14 index subdistricts with a high-risk of NiV emergence were identified. We found in our infectious network modeling that the infected subdistricts clustered in, or close to the central plain, within a range of $171 \mathrm{~km}$ from the source subdistricts. However, the virus may travel as far as $528.5 \mathrm{~km}\left(\mathrm{R}_{0}=5\right)$.

Conclusions: In conclusion, the risk of NiV dissemination through pig movement networks in Thailand is low but not negligible. The risk areas identified in our study can help the veterinary authority to allocate financial and human resources to where preventive strategies, such as pig farm regionalization, are required and to contain outbreaks in a timely fashion once they occur.
\end{abstract}

Keywords: Animal movement, Nipah virus, Network modeling, Spatial risk

\section{Background}

Nipah virus (NiV) is a negative-sense, single-stranded RNA virus. The virus belongs to the genus Henipavirus, family Paramyxoviridae [1]. In late September 1998, NiV first emerged amongst pig farmers and pigs in peninsular Malaysia [2]. The outbreak, which was associated with respiratory illness in pigs, and was first considered to be Japanese encephalitis [1]. Subsequently, a new virus closely related to Hendra virus, namely Nipah virus, was isolated [3].

\footnotetext{
* Correspondence: anuwat.wir@mahidol.edu

${ }^{7}$ Department of Clinical Sciences and Public Health, and the Monitoring and Surveillance Center for Zoonotic Diseases in Wildlife and Exotic Animals, Faculty of Veterinary Science, Mahidol University, Nakhon Pathom, Thailand Full list of author information is available at the end of the article
}

By mid-June 1999, 265 individuals had fallen ill, 105 of which passed away (39.6\% case-mortality rate). Consequently, over one million pigs were culled to control the outbreak $[1,3]$. The NiV epidemic in Malaysia was subsequently found to have been initiated from bats to pigs, which then spilled over to humans [4]. In pigs, the virus is highly contagious and the morbidity rate may reach $100 \%$, with a mortality rate of approximately $40 \%$. The infected animals manifested either respiratory or neurological signs depending on age. A high proportion of pigs were infected asymptomatically [5], suggesting silent zoonotic transmission.

Three years later, a different strain of NiV emerged in Bangladesh and India [6, 7]. These genetically distinct strains were mainly driven by bat-to-human and human-

(c) The Author(s). 2020 Open Access This article is licensed under a Creative Commons Attribution 4.0 International License, which permits use, sharing, adaptation, distribution and reproduction in any medium or format, as long as you give appropriate credit to the original author(s) and the source, provide a link to the Creative Commons licence, and indicate if changes were made. The images or other third party material in this article are included in the article's Creative Commons licence, unless indicated otherwise in a credit line to the material. If material is not included in the article's Creative Commons licence and your intended use is not permitted by statutory regulation or exceeds the permitted use, you will need to obtain permission directly from the copyright holder. To view a copy of this licence, visit http://creativecommons.org/licenses/by/4.0/. The Creative Commons Public Domain Dedication waiver (http://creativecommons.org/publicdomain/zero/1.0/) applies to the data made available in this article, unless otherwise stated in a credit line to the data. 
to-human transmission, and the outbreaks appeared to occur annually [8-10]. Recently, another episode of NiV an outbreak was identified in India in May 2018, which resulted in 21 deaths among 23 confirmed cases (18 with laboratory results) [11]. Unsurprisingly, there was evidence suggesting that the fruit bat was likely to be the primary reservoir host responsible for the outbreaks [12]. Basically, NiV transmission was believed to occur through the consumption of foods contaminated with bat urine, such as date palm sap [13]. Pigs appeared to be an amplifying host for the $1998 \mathrm{NiV}$ outbreaks in humans in Malaysia and Singapore, and direct contacts between bats and pigs were observed in the farm associated with the index case of the epidemic. Some of the evidence was piggeries placed under fruit trees, and halfconsumed fruits were found within the piggeries [14]. To date, the spillover of NiV into pig and human populations has only been observed in Malaysia, Singapore, India, and Bangladesh $[6,8,15,16]$. However, the genetic material of $\mathrm{NiV}$ in bats has been recovered from many more extended geographic locations, including Thailand [17, 18]. However, actual virus isolation has been limited.

In Thailand, bat-pig-human communities can be observed across the country, particularly in the central plain, a combination of the central and eastern regions. The distribution density of humans and pigs in relation to bat roosting sites is illustrated in Fig. 1. This kind of environment ideally facilitates $\mathrm{NiV}$ emergence and dissemination. It has been suggested that pig farms with low biosecurity around Bangkok were at risk for NiV infection, as colonies of flying foxes (bats in the genus Pteropus) are located close by [19]. Flying foxes are the predominant bats found across the central plain, the area where human population density is high (232.07 individuals $/ \mathrm{km}^{2}$ around the bat colonies). In addition, these bats are free to roam around the country, as bat hunting is completely prohibited, and bats are protected

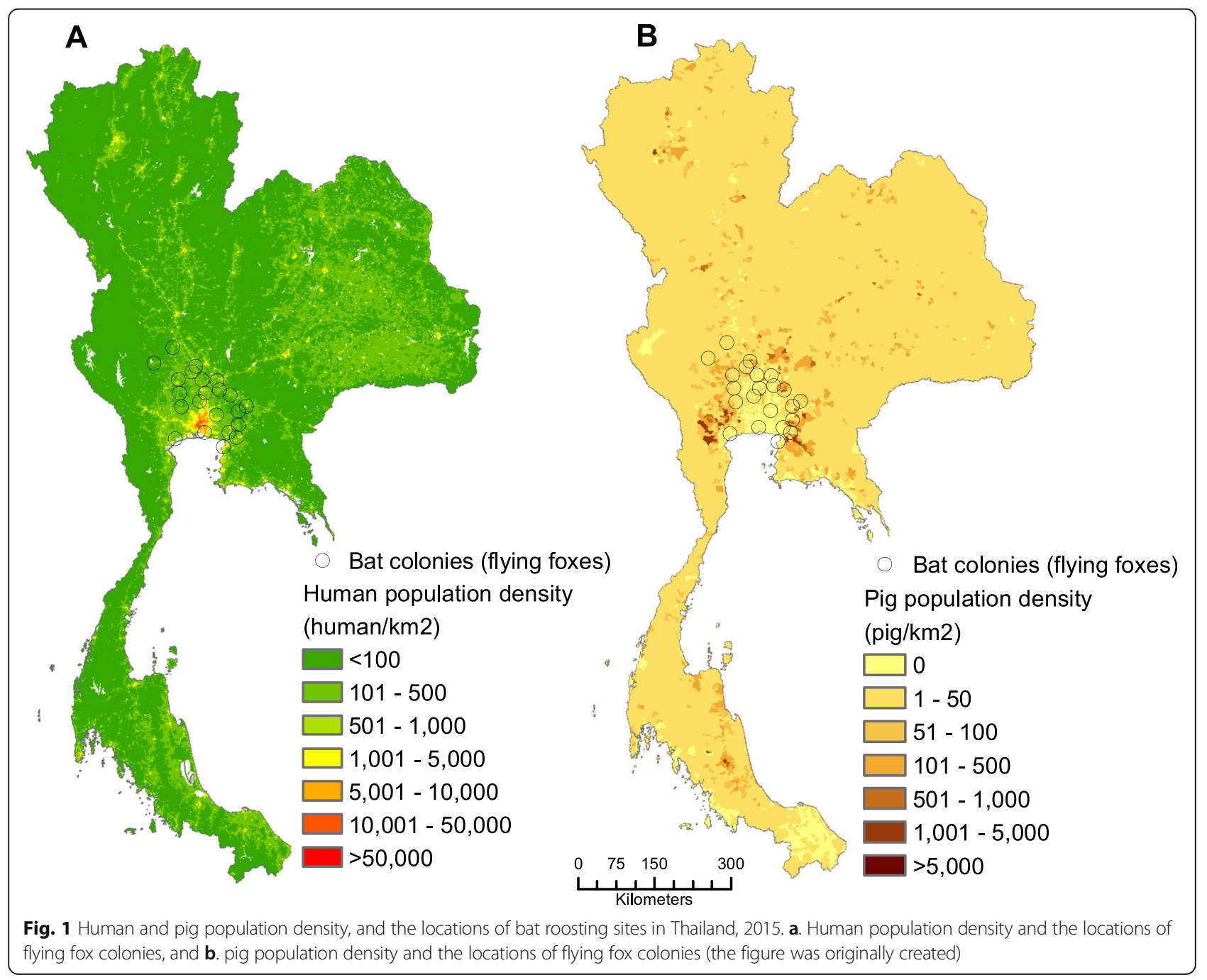


by the Wildlife Preservation and Protection Act, B.E. 2535 (1992). In the central plain, 22 colonies of flying foxes have been identified. Based on a satellite telemetry study, the foraging distances of these bats were estimated to be as far as $23.6 \mathrm{~km} \mathrm{[20].} \mathrm{Thirty-four} \mathrm{food}$ plants were consumed by the flying foxes, with the most common fruits recorded being mango, followed by banana and tamarind, respectively [20] and orchards of these fruits are found ubiquitously in the central plain of Thailand. Along their daily flying routes, the bats may occasionally visit some pig farms as previously evidenced in Malaysia [14]. Moreover, the genetic materials of both Malaysian and Bangladesh NiV strains have been detected in flying foxes (Pteropus lylei) [17].

The pig industry is an active and important business in Thailand. Pork meat is preferred in many Thai traditional dishes. Pig farming practice in Thailand is roughly divided into smallholder (a farm with less than 50 pigs) and large-scale (a farm with 50 pigs or more) farming systems, according to the Thai 'Good Agricultural Practices for Pig Farms' [21]. According to the Department of Livestock Development (DLD), a total of 10, 191,784 pigs were recorded nationwide in 2017. These pigs were raised in 180,606 farms, and most farmers (93.6\%) were considered smallholders [22]. In terms of pig types, the pigs in the farms can be either native, breeding, or fattening pigs. However, the majority of the smallholders raised native pigs, and their farms are generally located in rural areas to serve local consumption [21]. With limited budgets and resources, the biosecurity level in these small farms is relatively low [23]. Importantly, nearly half $(49.1 \%)$ of all the pigs in the country are found in the central plain [22]. Considering the home ranges of the flying foxes, human density and number of pigs, NiV epidemics may occur at any time. Surprisingly, no trace of NiV infection has been reported in pig or human populations in Thailand. However, the dynamic transmission of the virus is worth exploring.

Mathematical modeling is a tool to forecast the magnitude of disease outbreaks, and epidemic models have been constructed for different diseases in different locations, for instance, foot-and-mouth disease in the US [24] and Mexico [25] as well as rabies in Australia [26]. In many cases, infectious diseases were found to spread via contact networks, driven by animal trade and movement [27].

As $\mathrm{NiV}$ has not yet impacted pig populations in Thailand, it is critically important to foresee how the disease could spread so that relevant preventive measures, such as pig farm regionalization, can be implemented in the right geographical locations. Moreover, the preparedness for possible epidemics is essential for future disease prevention and control. The present study, therefore, aimed to identify the high-risk areas in which NiV may emerge and then model how the virus is likely to spread along the pig trade network nationwide so that budgets and workforce can be allocated effectively once an outbreak occurs.

\section{Results}

\section{Index subdistricts identification for the spread of NiV}

Based on our MCDA method, we identified 17 high-risk subdistricts together with 764, 442, and 870 medium, low, and very low-risk subdistricts, respectively. The high-risk subdistricts (Table 1) were overlapped with a list of subdistricts where pig movement activity was known to occur. The risk map of $\mathrm{NiV}$ detection is depicted in Fig. 2. The complete list of NiV occurrence probability for the 2093 subdistricts analyzed in this study is given in Additional file 1.

In the pig movement database, the translocation of pigs was recorded in 3292 subdistricts nationwide, and specifically, pig movement was found in 14 out of 17 identified high-risk subdistricts. The three subdistricts without any pig movement records were Asa, Bang Lao, and Bang Rakam, and therefore these subdistricts were excluded from the list of index subdistricts.

\section{NiV transmission modeling}

In this study, we varied the values of transmission rate $(\beta)$ and removal rate $(\gamma)$ as the actual values from field

Table 1 The list of high-risk subdistricts for NiV occurrence in Thailand

\begin{tabular}{llll}
\hline Geocode & Subdistrict & Province & $\begin{array}{l}\text { Probability of NiV } \\
\text { occurrence }\end{array}$ \\
\hline 240211 & Sao Cha-Ngo & Chachoengsao & 0.767383 \\
170403 & $\begin{array}{l}\text { Bang Nam } \\
\text { Chiao }\end{array}$ & Sing Buri & 0.744118 \\
260304 & Asa & Nakhon Nayok & 0.72053 \\
200602 & Na Phrathat & Chon Buri & 0.716989 \\
240107 & Khlong Chuk & Chachoengsao & 0.709265 \\
& Khachoe & Nakhon Nayok & 0.707236 \\
260307 & Phikun Ok & Ang Thong & 0.67296 \\
150306 & Norasing & Prachin Buri & 0.659102 \\
250106 & Bang Boribun & Chachoengsao & 0.637756 \\
240212 & Samet Nuea & Chachoengsao & 0.637532 \\
240106 & Bang Phai & Chon Buri & 0.631063 \\
200605 & Na Roek & Phra Nakhon Si & 0.619647 \\
140908 & Phra Kaeo & Ayutthaya & 0.615036 \\
& & Chon Buri & 0.614749 \\
200617 & Na Wang Hin & Chachoengsao & 0.613451 \\
241103 & Bang Lao & Nakhon Nayok & 0.612812 \\
150406 & Ba Kha & Ang Thong & 0.604876 \\
190502 & Nong Khwai So & Saraburi & \\
\hline
\end{tabular}




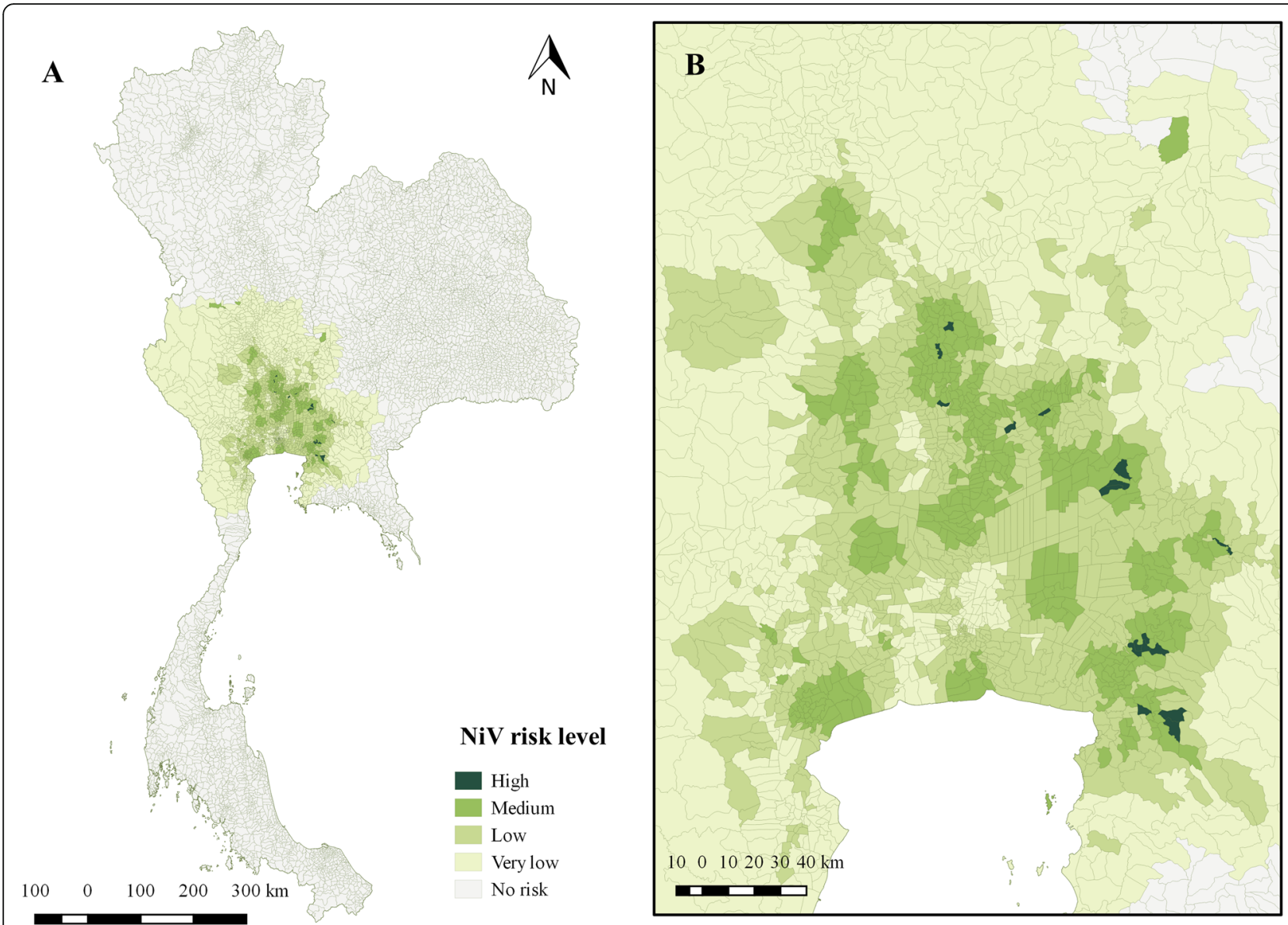

Fig. 2 The spatial risk level of NiV occurrence in the central plain of Thailand identified by the MCDA method. a. The distribution of the study subdistricts on the map of Thailand, and $\mathbf{b}$. The magnified map focusing on the central plain of Thailand (the figure was originally created)

observations are not available. Figure 3 illustrates how $\beta$ and the basic reproduction number $\left(\mathrm{R}_{0}\right)$ affect the $\mathrm{NiV}$ spreadability. Unsurprisingly, the more these two values increased, the more disease dissemination was observed. As shown in Fig. 3a, the probability that an index subdistrict may spread NiV outwards is around $1.00 \%$ (Inter-quartile range (IQR): 0.00-7.75\%). However, a probability higher than $75 \%$ was observed in three subdistricts, including Phra Kaeo (140908), Bang Nam Chiao (170403), and Bang Boribun (Geocode 250,106). As shown in Fig. 3b, our models showed that at an $R_{0}$ of 50 , the virus might spread from Bang Boribun (Geocode $250,106)$ to another 27 destination subdistricts. The median number of possible infected subdistricts, across all iterations, originating from one initial subdistrict is 1 (IQR: 0-2). Focusing on the average epidemic size (Fig. 3c), 40.95\% of all scenarios showed that NiV would never spread out. Interestingly, at an $\mathrm{R}_{0}$ of 2 , the virus may diffuse to two other subdistricts, whereas the median of all average epidemic size observed in our models (excluding the epidemic size of 0 ) is 1 (IQR: $1-1.10)$. Indeed, the maximum epidemic size (unaveraged) was found in Phra Kaeo (Geocode 140,908), and Bang Boribun (Geocode 250,106) subdistricts at a value of 5 . Figure $3 \mathrm{~d}$ shows the average risk estimated for each initial subdistrict. In general, the risk was less than $0.13 \%$. However, again higher risk was observed in Phra Kaeo (Geocode 140,908), and Bang Boribun (Geocode 250, 106) subdistricts at a maximum of 0.55 , and 0.18 , respectively.

The spatial distribution of $\mathrm{NiV}$ spread $\left(\mathrm{R}_{0}=5.0\right)$ through the pig trade chain and its corresponding risk level from our model is illustrated in Fig. 4. All 14 index subdistricts could infect 14 other subdistricts, with Pra Kaew subdistrict in Phra Kakhon Si Ayutthaya (Geocode 140,908), as the highest infectious index subdistrict. This subdistrict may spread the virus to other 9 subdistricts. Most of the infected subdistricts are clustered in, or close to the central plain of Thailand, within a range of $171 \mathrm{~km}$ from their source subdistricts (see Fig. 4a and c). 


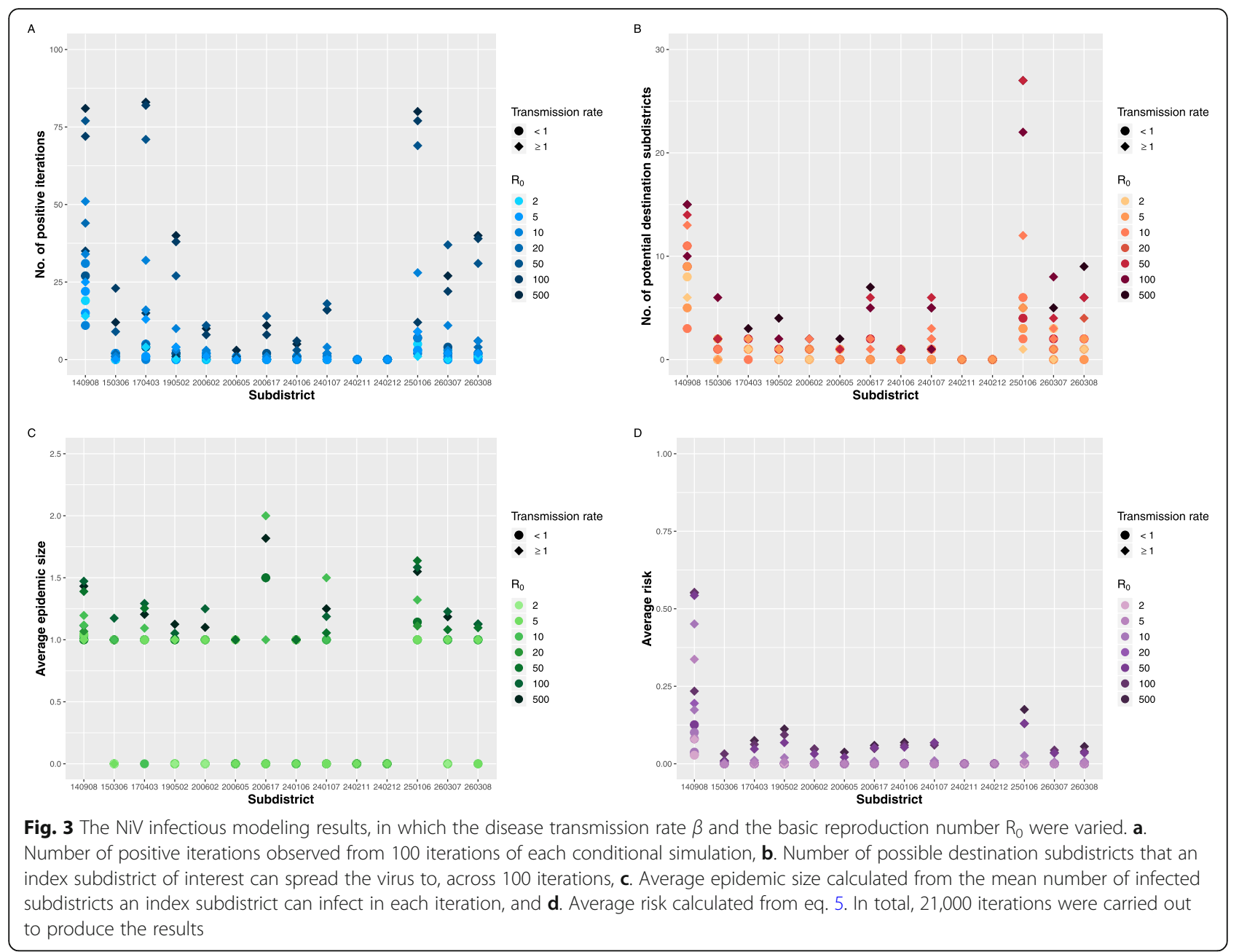

Interestingly, the subdistrict Pra Kaew could introduce $\mathrm{NiV}$ infected pigs much further to the Northern region, which are Chom Pu subdistrict in Lampang (Geocode 520, 106; $440.8 \mathrm{~km}$ ), and Dok Khamtai subdistrict in Phayao (Geocode 560,501; $528.5 \mathrm{~km}$ ), respectively (Fig. 4b).

\section{Discussion}

The present study primarily identified the spatial risk areas from which NiV may emerge, based on different contributing factors. The high-risk areas were then used to determine how NiV would spread across Thailand through the pig trade network. Our underlying assumption was that the virus would originate from the superimposed areas where both bat-pig spillover risk and concentrated pig trade activities were identified. Finally, disease transmission models were employed to illustrate how the virus would disseminate within and between subdistricts.

Based on our spatial risk modeling, the number of identified high-risk areas was only $0.3 \%(7 / 2093)$ of all subdistricts analyzed in the model. This might be the reason why an outbreak of $\mathrm{NiV}$ has not occurred in the pig population in Thailand. Importantly, our results are in line with a previous study using another spatial risk identification method, namely, potential surface analysis (PSA) [19]. High-risk areas were identified in the central plain of the country (Fig. 2), where a high density of pigs and bat colonies have been observed [19]. In addition, the genetic material of $\mathrm{NiV}$ has been recovered in the same region [17, 18]. In our study, we mainly used the multi-criteria decision analysis (MCDA) method, which is a knowledge-based approach using existing knowledge to create decision rules and to integrate them with some potential factors to ultimately identify the risks $[28,29]$. The MDCA methodology is an appropriate technique to be applied to this study, as the identification of relevant risk factors, their weights, and the way they increase the risk spatially may be defined more explicitly and thoroughly in using this approach 


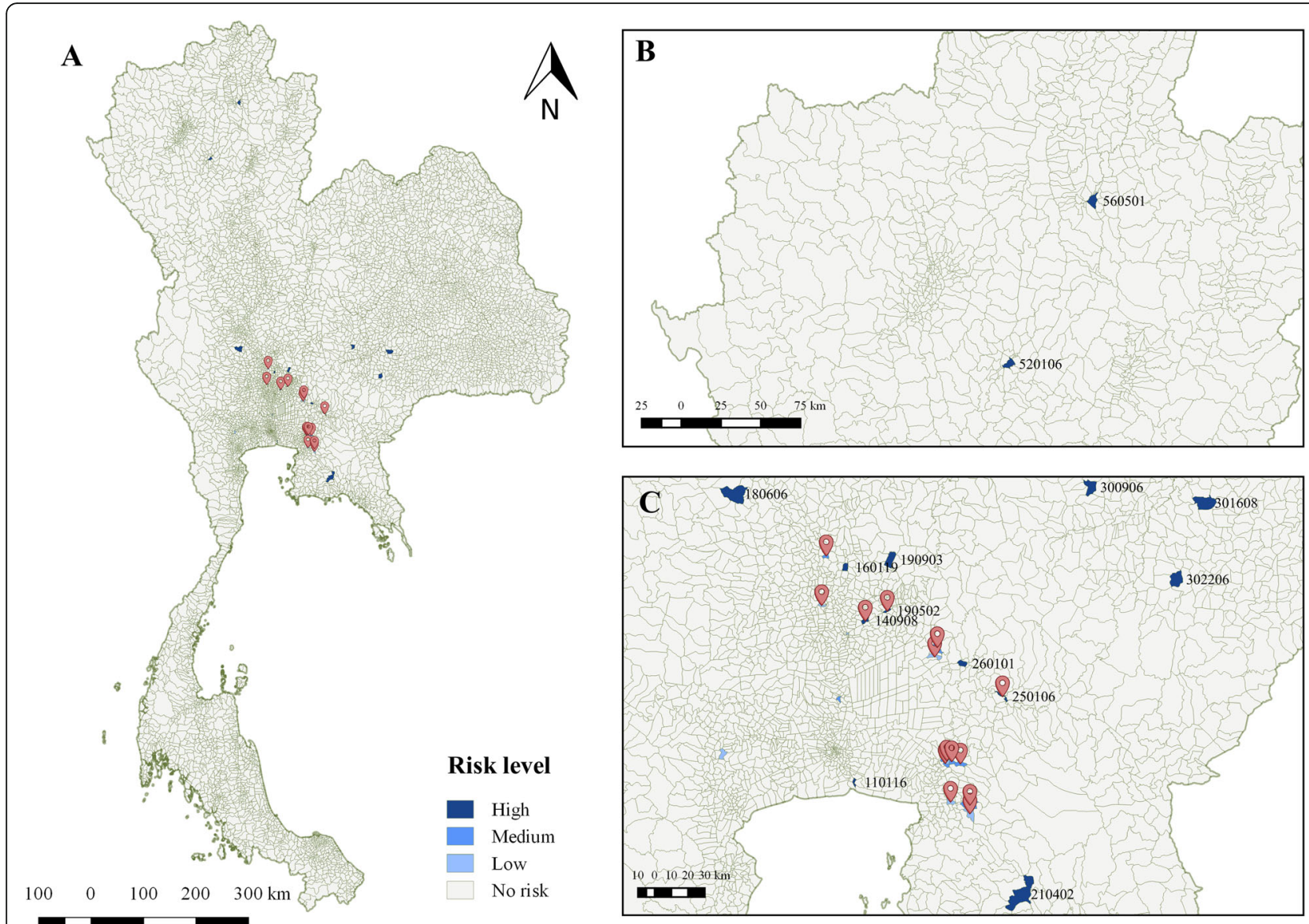

Fig. 4 Geographical distribution of the index subdistricts (red pinpoints) and the destination subdistricts with different risk levels, based on $R_{0}=5$ $\left(\beta=0.5, \gamma=0.1\right.$ ). The risk level was categorized as 'High' (greater than $\left.9.55 \times 10^{-4}\right)$, 'Medium' (greater than $2.13 \times 10^{-4}$ to $9.55 \times 10^{-4}$ ), 'Low' (greater than 0 to $2.13 \times 10^{-4}$ ), and 'No risk' (risk=0). a. The identified subdistricts are illustrated on the map of Thailand, $\mathbf{b}$. A magnified map focusing on the northern part of Thailand and, $\mathbf{c}$. A magnified map focusing on the central plain of Thailand where both index and destination subdistricts are concentrated (the figure was originally created)

[30]. The method has also been used in similar situations. For example, Paul and colleagues (2006) used MCDA to assess the suitability of areas for highly pathogenic avian influenza H5N1 in Thailand and applied this model to Cambodia [29].

As expected, outgoing pig movements were observed in $82.4 \%(14 / 17)$ of the identified high-risk subdistricts. The central plain was identified in a previous study as the main pig production area of Thailand, where different types of pig production systems are recognized [21]. The 14 subdistricts were then chosen to initiate NiV spread. In general, the probability that $\mathrm{NiV}$ can escape from the initial subdistricts is low except for the scenarios with extremely high $\mathrm{R}_{0}$ values (Fig. 3a). It is noteworthy that each index subdistrict can infect only a small number of other subdistricts (Fig. 3b). The virus was able to move to only one to two steps (Fig. 3c) before dying out, as no infected pigs were transported or no trade activities were observed in the dead-end subdistricts. Therefore, the overall risk of $\mathrm{NiV}$ transmission from these initial subdistricts is low (Fig. 3d) even with a high $R_{0}$.

In this study, we also tried to explore what would happen with extreme situations, for example, using $R_{0}$ values of 100 and 500. Surprisingly, we found that in many cases the risks were still low in such scenarios. Our models fully support the fact that the NiV has not emerged and spread in the pig populations in Thailand. Indeed, the DLD has conducted annual active surveillance for $\mathrm{NiV}$ detection in pigs in the country for more than 20 years, since the outbreak of NiV in Malaysia that emerged in 1998, and none has been detected. It is empirical and concrete evidence confirming that NiV has never emerged in our pig populations. Nonetheless, two high-risk initial subdistricts were identified in our models, including Phra Kaeo (Geocode 140,908) subdistrict, Phachi district, Phra Nakhon Si Ayutthaya province and Bang Boribun (Geocode 250,106) subdistrict, Mueang district, Prachinburi province. The former is a subdistrict with the second-highest number of 
outgoing pig transportation among the initial subdistricts. This explains the link between the number of animals moved and associated risk observed, as it has been suggested that the volume of animal movement is a key predictor of animal disease dissemination [31]. Moreover, the pigs exported from this subdistrict can travel quite far from the origin (Fig. 4b). The long-distance transportation of outgoing animal movements has been previously observed in different livestock species in Thailand, including cattle [32] and goats [33]. The socioeconomic motivations behind this trading behavior is worth exploring as moving animals across long distances is costly and time-consuming. There must be some convincing factors, for example, a higher selling rate compared to selling locally, that motivate animal traders to do so. To extend the study into this aspect, knowledge, and tools of social science and economics are needed. An insight into these motivations will help us in dealing with the behavior of the traders once an outbreak of infectious disease occurs.

We did face some potential limitations. Firstly, the pig movement data we used are the official animal movement data recorded electronically. This data recording system was designed to capture any inter-provincial livestock movements. However, the intra-provincial shipment of the animals is not recorded, and thus it is likely that we missed some hidden links that occurred within the provinces. This weakness was also pointed out in a previous study [34]. Thai veterinary authorities should reconstruct their procedures to include movement at the district or even subdistrict level. Secondly, we analyzed the spatial risk of $\mathrm{NiV}$ occurrence in less than one-third of all subdistricts in Thailand (2093/7416), as we focused on Thailand's central plain, which had been previously identified as a high contact zone between pigs and flying foxes [19]. To expand the model to cover the whole country, a field study to identify the current locations of bat colonies nationwide should be undertaken, together with increased data collection on other factors needed in the spatial risk model construction. However, the present study initially carried out a risk analysis of one of the hotspots identified in a previous study [35] using a more sophisticated analytical technique. Our methods could be applied more widely once more data are available. Thirdly, local transmission was not considered in our model. We exclusively focused on how NiV spread along the trade chain. Indeed, the virus may disperse locally by other means. A more sophisticated modeling approach, such as an individual-based system at an animal or farm level, is recommended. Fourthly, we did not include other factors that may influence how NiV spreads in the pig population, such as meteorological effects and seasonality. However, we intended to produce an initial model focusing on the spread of the virus through the pig movement. A future study, including other contributing factors, is recommended. Fifthly, the $\beta$ and $\gamma$ values of NiV transmission are not known. We used different values of these parameters to explore the likelihood of disease spread. If we have better knowledge of these parameters in the future, the model will be more accurate and suitable for an outbreak situation. Sixthly, the epidemiological model itself always comes with some general limitations. In the MCDA framework, as it is a knowledge-based approach, the subjectivity of the method derived from the involvement of experts' opinions might be a significant limitation. Nonetheless, this approach is still practical, especially in the case that actual field data is unavailable, as in our case. In the SEIR model, the population is assumed to be homogeneously mixed while the actual pig population in the subdistrict is further divided into the farm level. However, the SEIR model is still one of the best choices when we need to work with big data as it is less time-consuming compared to other more complex models like an individualbased framework. The last and the most important limitation found in our study was that Thailand has never experienced an NiV epidemic. The NiV outbreak in pig populations in Malaysia has been the only recognized attack in veterinary history so far. To contain that particular devastating epidemic, millions of pigs were immediately culled $[1,4]$. It was too rapid to observe any epidemiological characteristics of $\mathrm{NiV}$ propagation. Consequently, we need to vary different epidemic parameters to visualize different outbreak scenarios that are likely to occur. However, it is not possible to validate our assumptions. The best we can do is to quantify the risk and promptly prepare for the potential outbreaks. Nonetheless, our simulation framework is exploitable as a baseline model to examine the effectiveness of control strategies, and to suggest some practical contingency plans. In addition, our model is able to identify the areas where pig farming practices should be improved to prevent the occurrence of an $\mathrm{NiV}$ outbreak. In this study, we produced a simulation framework that is usable as a baseline structure for any interventional modeling. We acknowledge here that our model did not consider the nature of the pig movement. A future study may simulate animal movement according to the intended purpose, such as to a slaughterhouse and include relevant parameters for the spread of the virus. This will make the model more realistic, but it requires a valid set of field data to do so.

\section{Conclusions}

The risk of NiV dissemination through pig movement networks in Thailand is low but not negligible as we have a perfect environment for $\mathrm{NiV}$ emergence in the country. The risk areas identified in our study may help 
veterinary authorities to allocate financial and human resources to where preventive strategies, such as pig farm regionalization are required, and to contain outbreaks in a timely fashion once they occur.

\section{Methods}

Index subdistricts identification for the spread of NiV

The present study focused on the transmission of $\mathrm{NiV}$ at the subdistrict level, the smallest administrative unit in Thailand with standard geocodes [36]. We focused on 2093 subdistricts located in the central plain of Thailand, where bat colonies and pig farms are highly concentrated. The spatial risk of NiV emergence was assessed using the multi-criteria decision analysis (MCDA) method, and the results were published previously [35]. In this study, we sought to expand on those results. Briefly, we invited 20 experts in epidemiology, virology, pig farming systems, and bat ecology to attend a workshop for the decision-making process. The experts identified i) spatial risk factors of $\mathrm{NiV}$ transmission including bat preferred areas, distance to the nearest bat colony, pig population density, distance to the nearest forest, distance to the nearest orchard, distance to the nearest water body, and human population density, ii) the experts identified the association between the values of each factor and the suitability of $\mathrm{NiV}$ distribution by using fuzzy membership functions, and iii) technique. The details of all steps are explained in [35]. Subsequently, the geometric information system (GIS) method with a weighted linear combination (WLC) was used to combine all spatial risk layers to generate a final estimated map. The risk was divided into five levels according to the probability of disease occurrence, namely very high (0.8-1), high (0.6-0.8), medium (0.4-0.6), low (0.2$0.4)$, and very low $(0.0-0.2)$. The high-risk subdistricts $(>0.6)$ were then overlaid on the subdistricts with pig movement activities, based on the national animal movement database of the DLD, to identify the subdistricts that $\mathrm{NiV}$ may initiate the transmission through the pig movement network (Fig. 5).

\section{NiV transmission modeling Within subdistricts}

An official database of pig population at the subdistrict level in Thailand in 2017 was obtained from the DLD [22]. The data was then used as a baseline in our NiV infectious modeling within each subdistrict. An index subdistrict was chosen from the list prepared from the previous step. An NiV infected pig was then introduced into the selected subdistrict. A Susceptible-ExposedInfectious-Removed (SEIR) model was employed, as shown in eq. 1. We varied the parameters to deal with uncertainty by calculating the basic reproduction number $\mathrm{R}_{0}$ $(\beta / \gamma)$, as shown in Table 2 . Note that only the $R_{0}>1$ was

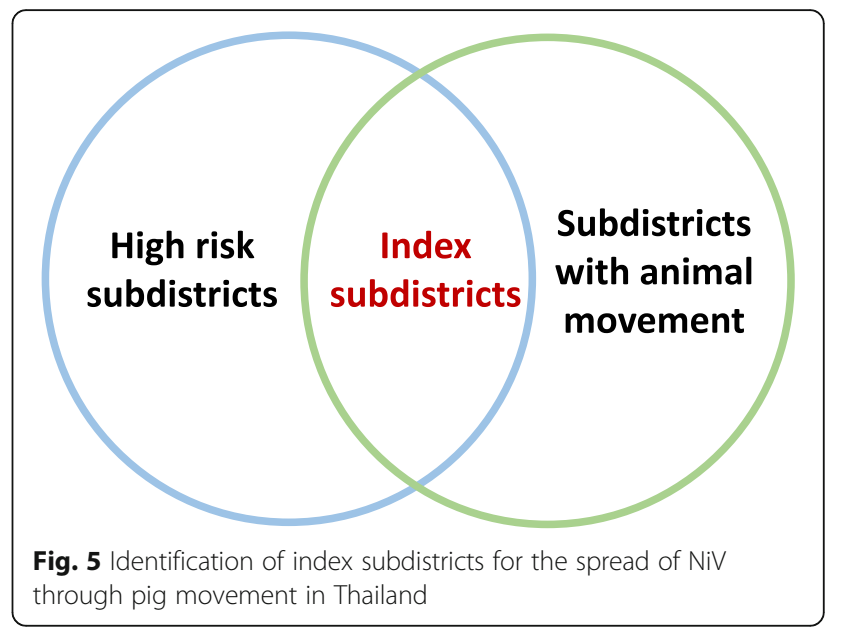

used, as this allows the disease to spread [37]. In this model, we followed a latent period $(\sigma)$ of 6 days based on a previous study [37]. The model was constructed on a weekly basis. At the end of the week, a specific number of pigs were designated to a subdistrict that was randomly chosen from the destinations list recorded in the pig movement database. The within subdistrict transmission is conceptualized as demonstrated in Fig. 6.

$$
\begin{aligned}
& \frac{\mathrm{dS}}{\mathrm{dt}}=-\frac{\beta \mathrm{SI}}{\mathrm{N}} \\
& \frac{\mathrm{dE}}{\mathrm{dt}}=\frac{\beta \mathrm{SI}}{\mathrm{N}}-\sigma \mathrm{E} \\
& \frac{\mathrm{dI}}{\mathrm{dt}}=\sigma \mathrm{E}-\gamma \mathrm{I} \\
& \frac{\mathrm{dR}}{\mathrm{dt}}=\gamma \mathrm{I}
\end{aligned}
$$

, where $\mathrm{S}=$ Susceptible, $\mathrm{E}=$ Exposed, $\mathrm{I}=$ Infectious, $\mathrm{R}=$ Removed, $\beta=$ transmission rate, $\gamma=$ removal rate and $\sigma=$ latent period. The model is governed by a differential ordinary equation.

The susceptible $(\mathrm{S})$ is the subpopulation without immunity which is capable of being infected, exposed (E) is the population that is already infected, but not yet infectious (unable to spread the virus), infectious (I) develops

Table 2 The $R_{0}$ values varied from different $\beta$ and $\gamma$ values. The values higher than 1 were used in the NiV spread simulation

\begin{tabular}{llllll}
\hline $\begin{array}{l}\text { Transmission } \\
\text { rate }(\boldsymbol{\beta})\end{array}$ & \multicolumn{6}{l}{ Removal rate $(\boldsymbol{\gamma})$} & & \\
\cline { 2 - 6 } & 0.01 & 0.05 & 0.1 & 0.5 & 1 \\
\hline $\mathbf{0 . 0 5}$ & 5 & 1 & 0.5 & 0.1 & 0.05 \\
$\mathbf{0 . 1}$ & 10 & 2 & 1 & 0.2 & 0.1 \\
$\mathbf{0 . 5}$ & 50 & 10 & 5 & 1 & 0.5 \\
$\mathbf{1}$ & 100 & 20 & 10 & 2 & 1 \\
$\mathbf{5}$ & 500 & 100 & 50 & 10 & 5 \\
\hline
\end{tabular}




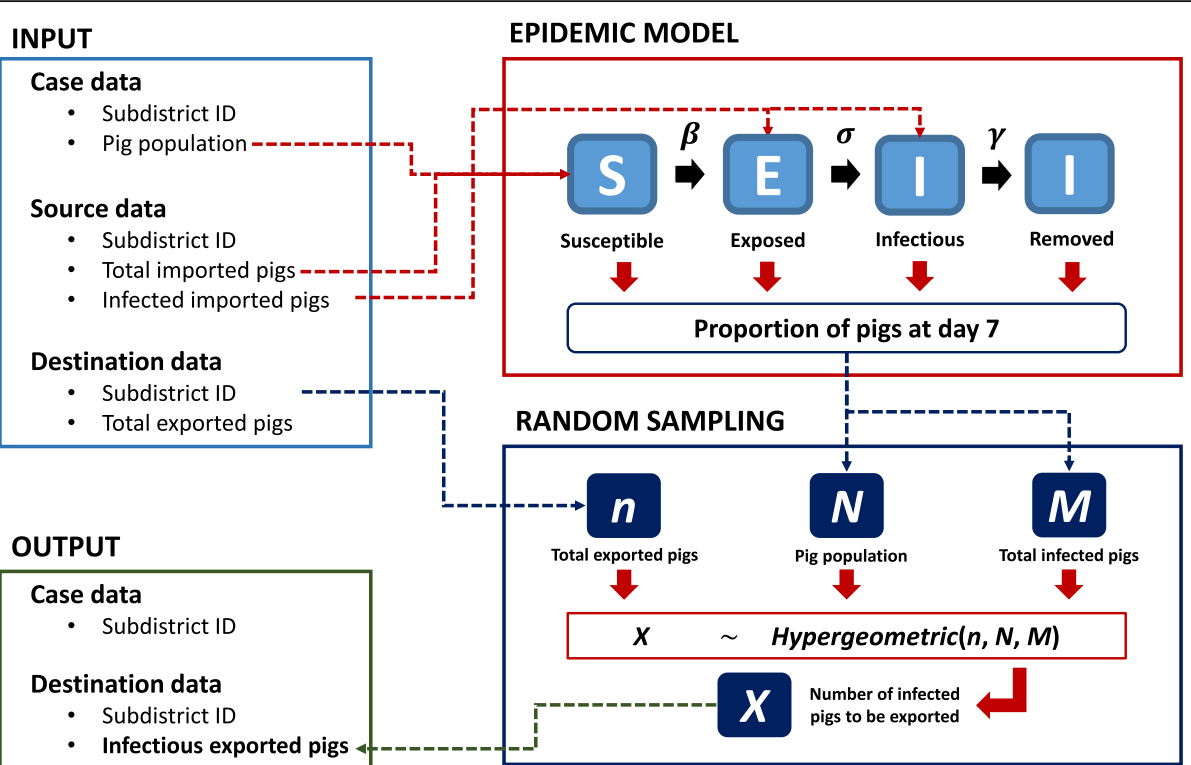

Fig. 6 Conceptual framework of NiV transmission within a subdistrict

from exposed individuals after a certain period (latent period) They can spread the virus to susceptible individuals and removed $(\mathrm{R})$ is defined here as pigs that die or recover from the infection.

\section{Between subdistricts}

The between subdistrict modeling of the NiV spread is conceptualized in Fig. 7. To model pig movement from a source subdistrict i $\left(S_{i}\right)$, a list of modeled destination subdistricts $(M)$ and the number of transported pigs $(N)$ are generated. The number of weekly pig movements of $S_{i} \quad\left(n_{i}\right)$ is generated with the following Poisson distribution:

$$
n_{i} \sim \operatorname{Pois}\left(\lambda_{i}\right)
$$

; where $\lambda_{i}$ is the mean number of weekly pig movements of $S_{i}$ derived from the animal movement dataset. Let total $j$ subdistricts (D) be the members of a set of all possible destination subdistricts of $S_{i}\left(D_{P}\right)$. The probability of $D_{j}$ being selected as a destination subdistrict in the modeled pig movement $\left(p_{j}\right)$ is calculated as:

$$
p j=\frac{f_{j}}{F}
$$

; where $f_{j}$ is an annual pig movement frequency from $S_{i}$ to $D_{j}$, and $F$ is the total number of annual pig

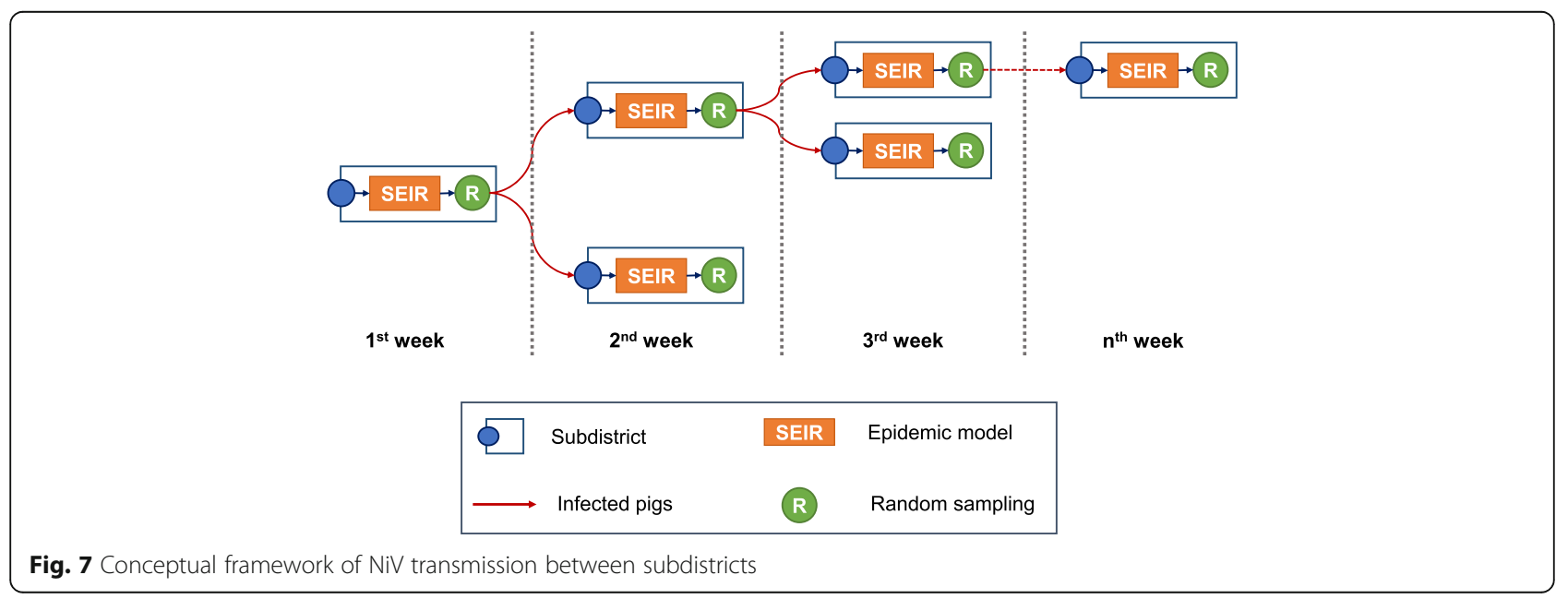


movement frequency of $S_{i}$ to all destinations. Then, total $n_{i}$ destination subdistricts are randomly selected from $D_{P}$ as members of $\mathrm{M}$ with their respective probabilities $p$. Finally, the number of pigs transported $\left(N_{k}\right)$ from $S_{i}$ to a subdistrict of destination $\mathrm{k}\left(M_{k}\right)$ is generated following a normal distribution:

$$
\mathrm{N}_{\mathrm{k}} \sim \operatorname{Normal}\left(\overline{\mathrm{X}}_{\mathrm{k}}, s_{\mathrm{k}}\right)
$$

; where $X_{k}$ and $s_{k}$ are the mean and standard deviation of the number of pigs transported from $S_{i}$ to $M_{k}$ per movement, according to the actual animal movement dataset.

We repeated the whole process for all subdistricts listed as potentially high-risk areas for the NiV spread. In each index subdistrict, we recorded four main outputs; (i) number of positive iterations in which the NiV can spread out from the index subdistricts, (ii) number of potential destination subdistricts, the aggregation of all possible subdistricts that $\mathrm{NiV}$ reached across iterations, (iii) average epidemic size which is the mean number of infected subdistricts resulting from an index subdistrict in each iteration, and (iv) average risk $(\pi)$ which is calculated from the following equation:

$$
\pi=\frac{1}{N_{\pi}} \sum_{i=1}^{I} \sum_{j=1}^{J} \pi_{i j}, \pi_{i j}>0
$$

; where $I$ and $J$ denotes the number of infected subdistricts resulting from an index subdistrict, and the number of total iterations, respectively. While $\pi_{i j}$ is the risk of subdistrict $\mathrm{i}$ of the $\mathrm{j}^{\text {th }}$ iteration, and $N_{\pi}$ is the total number of $\pi_{i j}>0$.

We used programming language $\mathrm{R}$ version 3.5.1 in the spatial risk analysis and the within subdistrict modeling of $\mathrm{NiV}$ spread. The between subdistrict modeling of pig trade and the NiV dissemination were mechanized by Visual studio code with python version 3.6.8. The pig movement and disease transmission were stochastically simulated in 100 iterations each. In total, 21,000 iterations were carried out to produce the results. The risk maps were visualized with QGIS application version 2.18.24.

\section{Supplementary information}

Supplementary information accompanies this paper at https://doi.org/10. 1186/s12917-020-02502-4.

Additional file 1: Table S1. The list of high risk subdistricts for NiV occurrence at subdistrict level. Table S2. The list of medium risk subdistricts for NiV occurrence at subdistrict level. Table S3. The list of low risk subdistricts for NiV occurrence at subdistrict level. Table S4. The list of very low risk subdistricts for NiV occurrence at subdistrict level.

\section{Abbreviations}

BE: Buddhist Era; DLD: Department of Livestock Development; GIS: Geographic information system; IQR: Inter-quartile range; MCDA: Multicriteria decision analysis; NiV: Nipah virus; PSA: Potential surface analysis;
RNA: Ribonucleic acid; SEIR: Susceptible-exposed-infectious-removed; US: United States; WLC: Weighted linear combination

\section{Acknowledgements}

We are grateful to the staff of the Bureau of Disease Control and Veterinary Services, Department of Livestock Development of Thailand, for data support. We thank Prof. Dr. Duncan R. Smith, Institute of Molecular

Biosciences, Mahidol University for copyediting our manuscript.

\section{Authors' contributions}

AW conceived and designed the study. PW, WK, SK and KS performed mathematical modeling and relevant statistical analysis. WT generated the raw data and performed spatial analysis with contributions from AW and PW AW and PW drafted the paper, in which WT, WK, SK, KS, WK and KW critically reviewed. WT, WK and KW provided data. All authors read and approved the final manuscript.

\section{Funding}

Part of this work was supported through the USAID/FAO grant (LOA/RAP/ 2016/32). The funder had no role in study design, data collection and analysis, decision to publish, or preparation of the manuscript.

\section{Availability of data and materials}

The data that support the findings of this study are available from the Department of Livestock Development, but restrictions apply to the availability of these data, which were used under license for the current study, and so are not publicly available. Data are, however, available from the authors upon reasonable request and with permission of the Department of Livestock Development.

\section{Ethics approval and consent to participate}

This study was approved by the Research Committee of the Bureau of Disease Control and Veterinary Services, Department of Livestock Development, Thailand.

Consent for publication

Not Applicable.

\section{Competing interests}

The authors declare that they have no competing interests.

\section{Author details}

${ }^{1}$ Université Clermont Auvergne, INRAE, VetAgro Sup, UMR EPIA, 63122 Saint-Genès-Champanelle, France. ${ }^{2}$ Université de Lyon, INRAE, VetAgro Sup, UMR EPIA, 69280 Marcy l'Etoile, France. ${ }^{3}$ Department of Livestock Development (DLD), Bangkok, Thailand. ${ }^{4}$ Faculty of Information and Communication Technology, Mahidol University, Nakhon Pathom, Thailand. ${ }^{5}$ Food and Agriculture Organization of the United Nations, Global Emergency Centre for Transboundary Animal Diseases (ECTAD), Rome, Italy. ${ }^{6}$ Food and Agriculture Organization of the United Nations, Regional Office for Asia and the Pacific, Bangkok, Thailand. ${ }^{7}$ Department of Clinical Sciences and Public Health, and the Monitoring and Surveillance Center for Zoonotic Diseases in Wildlife and Exotic Animals, Faculty of Veterinary Science, Mahidol University, Nakhon Pathom, Thailand.

Received: 18 April 2019 Accepted: 29 July 2020

Published online: 24 August 2020

\section{References}

1. Chua KB, Coldsmith S, Ling AE. Nipah virus: a recently emergent deadly paramyxovirus. Science. 2000;288:1432-5.

2. Wong KT, Shieh WJ, Zaki SR, Tan CT. Nipah virus infection, an emerging paramyxoviral zoonosis. Springer Semin Immunopathol. 2002;24:215-28.

3. Field H, Young P, Yob JM, Mills J, Hall L, Mackenzie J. The natural history of Hendra and Nipah viruses. Microbes Infect. 2001;3:307-14.

4. Pulliam JRC, Field HE, Olival KJ. Nipah virus strain variation [5]. Emerg Infect Dis. 2005;11:1978-9.

5. Nor M, Gan C, Ong B. Nipah virus infection of pigs in peninsular Malaysia epidemiological findings. Rev Sci Tech. 2000;19:160-5. 
6. Chadha MS, Comer JA, Lowe L, Rota PA, Rollin PE, Bellini WJ, et al. Nipah virus-associated encephalitis outbreak, Siliguri, India. Emerg Infect Dis. 2006; 12:235-40.

7. Luby SP, Hossain MJ, Gurley ES, Ahmed BN, Banu S, Khan SU, et al. Recurrent zoonotic transmission of Nipah virus into humans, Bangladesh, 2001-2007. Emerg Infect Dis. 2009;15:1229-35.

8. Hsu VP, Hossain MJ, Parashar UD, Ali MM, Ksiazek TG, Kuzmin I, et al. Nipah virus encephalitis reemergence, Bangladesh. Emerg Infect Dis. 2004;10:2082-7.

9. Montgomery JM, Hossain MJ, Gurley E, Carroll DS, Croisier A, Bertherat E, et al. Risk factors for Nipah virus encephalitis in Bangladesh. Emerg Infect Dis. 2008;14:1526-32.

10. Nikolay B, Salje H, Hossain MJ, Khan AKMD, Sazzad HMS, Rahman M, et al. Transmission of nipah virus - 14 years of investigations in Bangladesh. $\mathrm{N}$ Engl J Med. 2019:380:1804-14.

11. Arunkumar G, Chandni R, Mourya DT, Singh SK, Sadanandan R, Sudan P, et al. Outbreak investigation of nipah virus disease in Kerala, India, 2018. J Infect Dis. 2019;219:1867-78.

12. Yadav PD, Shete AM, Kumar GA, Sarkale P, Sahay RR, Radhakrishnan C, et al. Nipah virus sequences from humans and bats during Nipah outbreak, Kerala, India, 2018. Emerg Infect Dis. 2019;25:1003-6.

13. Rahman MA, Hossain MJ, Sultana S, Homaira N, Khan SU, Rahman M, et al. Date palm sap linked to nipah virus outbreak in Bangladesh, 2008. VectorBorne Zoonotic Dis. 2012;12:65-72.

14. Chua KB, Chua BH, Wang CW. Anthropogenic deforestation, El Niño and the emergence of Nipah virus in Malaysia. Malays J Pathol. 2002;24:15-21.

15. Paton NI, Leo YS, Zaki SR, Auchus AP, Lee KE, Ling AE, et al. Outbreak of Nipah-virus infection among abattoir workers in Singapore. Lancet. 1999; 354:1253-6.

16. Chua KB, Goh KJ, Wong KT, Kamarulzaman A, Tan PS, Ksiazek TG, et al. Fatal encephalitis due to Nipah virus among pig-farmers in Malaysia.Lancet. 1999; 354:1257-9.

17. Wacharapluesadee S, Boongird K, Wanghongsa S, Ratanasetyuth N, Supavonwong P, Saengsen D, et al. A longitudinal study of the prevalence of Nipah virus in pteropus lylei bats in Thailand: evidence for seasonal preference in disease transmission. Vector-Borne Zoonotic Dis. 2010;10:183-90.

18. Wacharapluesadee S, Lumlertdacha B, Boongird K, Wanghongsa S, Chanhome L, Rollin P, et al. Bat Nipah virus, Thailand. Emerg Infect Dis. 2005;11:1949-51.

19. Thanapongtharm W, Linard C, Wiriyarat W, Chinsorn P, Kanchanasaka B, Xiao $X$, et al. Spatial characterization of colonies of the flying fox bat, a carrier of Nipah virus in Thailand. BMC Vet Res. 2015;11:1-14.

20. Weber N, Duengkae P, Fahr J, Dechmann DK, Phengsakul P, Khumbucha W, et al. High-resolution GPS tracking of Lyle's flying fox between temples and orchards in Central Thailand. J Wildl Manag. 2015;79:957-68.

21. Thanapongtharm W, Linard C, Chinson P, Kasemsuwan S, Visser M, Gaughan $A E$, et al. Spatial analysis and characteristics of pig farming in Thailand. BMC Vet Res. 2016;12:1-15. https://doi.org/10.1186/s12917-016-0849-7.

22. Department of Livestock Development of Thailand. Number of livestock in Thailand. 2017. http://www.oic.go.th/FILEWEB/CABINFOCENTER28/ DRAWER090/GENERAL/DATA0000/00000061.PDF. Accessed 14 Apr 2019.

23. National Bureau of Agricultural Commodity and Food Standards of Thailand. Good Agricultural Practices For Pig Farm. 2015. https://www.acfs.go.th/ standard/download/GUIDANCE-GAP-PIG-FARM.pdf.

24. Ward MP, Highfield LD, Vongseng P, Graeme GM. Simulation of foot-andmouth disease spread within an integrated livestock system in Texas, USA Prev Vet Med. 2009;88:286-97.

25. Nogueira L, Marsh TL, Tozer PR, Peel D. Foot-and-mouth disease and the Mexican cattle industry. Agric Econ. 2011;42(SUPPL. 1):33-44.

26. Johnstone-Robertson SP, Fleming PJS, Ward MP, Davis SA. Predicted spatial spread of canine rabies in Australia. PLoS Negl Trop Dis. 2017;11:1-21.

27. Lentz HHK, Koher A, Hövel P, Gethmann J, Sauter-Louis C, Selhorst T, et al. Disease spread through animal movements: a static and temporal network analysis of pig trade in Germany. PLoS One. 2016;11:1-32

28. Stevens KB, Pfeiffer DU. Spatial modelling of disease using data- and knowledge-driven approaches. Spat Spatiotemporal Epidemiol. 2011;2:125-33.

29. Paul MC, Goutard FL, Roulleau F, Holl D, Thanapongtharm W, Roger FL, et al. Quantitative assessment of a spatial multicriteria model for highly pathogenic avian influenza H5N1 in Thailand, and application in Cambodia. Sci Rep. 2016;6:1-10
30. Huang IB, Keisler J, Linkov I. Multi-criteria decision analysis in environmental sciences: ten years of applications and trends. Sci Total Environ. 2011;409: 3578-94.

31. Fèvre EM, Bronsvoort BMDC, Hamilton KA, Cleaveland S. Animal movements and the spread of infectious diseases. Trends Microbiol. 2006;14:125-31.

32. Wiratsudakul A, Sekiguchi S. The implementation of cattle market closure strategies to mitigate the foot-and-mouth disease epidemics: a contact modeling approach. Res Vet Sci. 2018;121:76-84.

33. Chintrakulchai $P$, Vuttichai $S$, Wiratsudakul A. Goat movement network analysis and its implications for caprine brucellosis propagation in Nonthaburi Province, Thailand. Asian Pacific J Trop Dis. 2017;7:477-81.

34. Noopataya S, Thongratsakul S, Poolkhet C. Social network analysis of cattle movement in Sukhothai province, Thailand: a study to improve control measurements. Vet Med Int. 2015;2015:1-6.

35. Thanapongtharm W, Paul MC, Wiratsudakul A, Wongphruksasoong V, Kalpravidh W, Wongsathapornchai K, et al. A spatial assessment of Nipah virus transmission in Thailand pig farms using multi-criteria decision analysis. BMC Vet Res. 2019;15:1-13.

36. Digital Government Development Agency of Thailand. Thai subdistrict coordinates. 2019. https://data.go.th/DatasetDetail.aspx?id=c6d42e1b-3219-4 7e1-b6b7-dfe914f27910. Accessed 14 Apr 2019.

37. Dietz K. The estimation of the basic reproduction number for infectious diseases. Stat Methods Med Res. 1993;2:23-41.

\section{Publisher's Note}

Springer Nature remains neutral with regard to jurisdictional claims in published maps and institutional affiliations.
Ready to submit your research? Choose BMC and benefit from:

- fast, convenient online submission

- thorough peer review by experienced researchers in your field

- rapid publication on acceptance

- support for research data, including large and complex data types

- gold Open Access which fosters wider collaboration and increased citations

- maximum visibility for your research: over $100 \mathrm{M}$ website views per year

At BMC, research is always in progress.

Learn more biomedcentral.com/submissions 